\title{
Examination of Ambient Temperature Variations Effects on Predicted Fluid Temperatures in Vertical Boreholes
}

\section{Massimo Cimmino}

\begin{abstract}
A fully-coupled model of geothermal bore fields is presented, taking into account the axial variations of borehole wall temperatures and heat extraction rates along the borehole lengths, fluid temperature variations inside the U-tubes and depth-variation of ground temperature due to seasonal ambient temperature variations. The model incorporates an analytical finite line source model to calculate borehole wall temperatures. A steady-state analytical solution is used to calculate fluid temperatures from arbitrary borehole wall temperature profiles. Ground temperatures are calculated from a onedimensional analytical solution to beat conduction in semi-infinite media with varying surface temperature. A system of equations is built and solved in the Laplace domain. The specific case of boreholes connected in series is discussed. Different assumptions for time- and depth-variation of ground temperatures are compared. Results show that time-varying uniform ground temperatures is accurate for simulations, with differences in predicted fluid temperatures within $1.5 \%$ of time-varying non-uniform ground temperatures.
\end{abstract}

\section{INTRODUCTION}

The design of geothermal bore fields coupled to geothermal heat pump systems relies on the accurate simulation of fluid temperatures in the boreholes. At short time scales, heat transfer processes in geothermal boreholes are affected by the thermal capacities of the circulating fluid and the grout material as well as the travel time of the fluid inside the boreholes. The heat interaction between the boreholes and the ground is then radially onedimensional. At larger time-scales, axial conduction effects due to the finite borehole length and thermal interaction between boreholes become significant. The ground surface temperature is often considered constant and equal to the undisturbed ground temperature in analytical models, since the penetration depth of seasonal ground temperature variations due to varying ambient temperatures covers only a small portion of the borehole length. For short boreholes, however, the ground temperature variation covers a greater portion of the boreholes and may significantly impact on the outlet fluid temperatures. This study examines the effect of ambient temperature variations on the predicted fluid temperatures in geothermal boreholes.

Fluid and ground temperature variations in geothermal bore fields are typically calculated by the temporal superposition of thermal response factors, or g-functions. Eskilson (1987) evaluated thermal response factors from 
numerical finite difference simulations. These thermal response factors represent the dimensionless temperature drop in a bore field with constant total heat extraction rate. g-Functions are implemented in several ground heat exchanger design tools and energy simulation programs (Hellström and Sanner 1994; Spitler 2000; Fisher, et al. 2006; Liu and Hellstrom 2006).

Finite line source solutions (Zeng, et al. 2002; Lamarche and Beauchamp 2007; Claesson and Javed 2011) have been proposed to estimate $\mathrm{g}$-functions and simulate geothermal bore fields. Since the finite line source solution assumes a uniform heat extraction or injection rate along the boreholes, contrary to the uniform borehole wall temperature used by Eskilson (1987), thermal response factors obtained from the finite line source solution tend to overestimate Eskilson's g-functions. Cimmino et al. (2013) and Cimmino and Bernier (2014) proposed a method, based on the finite line source, to consider the variation of the heat extraction rates along the borehole lengths and obtain thermal response factors for uniform borehole wall temperatures. A similar approach was used by Lazzarotto (2016) and Lazzarotto and Björk (2016) for tilted boreholes. The finite line source method has also been applied to geothermal boreholes with groundwater advection (Molina-Giraldo, et al. 2011) and boreholes connected in series (Marcotte and Pasquier 2014).

The condition of uniform borehole wall temperature may lead to inaccuracies when simulating geothermal bore fields. Cimmino (2015) proposed a method based on the finite line source solution to calculate thermal response factors of bore fields with equal inlet fluid temperature for all boreholes. The finite line source solution was coupled to a steady-state solution of the fluid temperature profiles in the U-tube pipes. It was shown that the value of thermal response factors are sensitive to the borehole thermal resistance. Furthermore, the condition of constant ground surface temperature may also lead to inaccuracies when predicting fluid and ground temperatures in geothermal systems (Bandos, et al. 2009; Bandos, et al. 2011; Rivera, et al. 2015; Zarrella and Pasquier 2015; Rivera, et al. 2016).

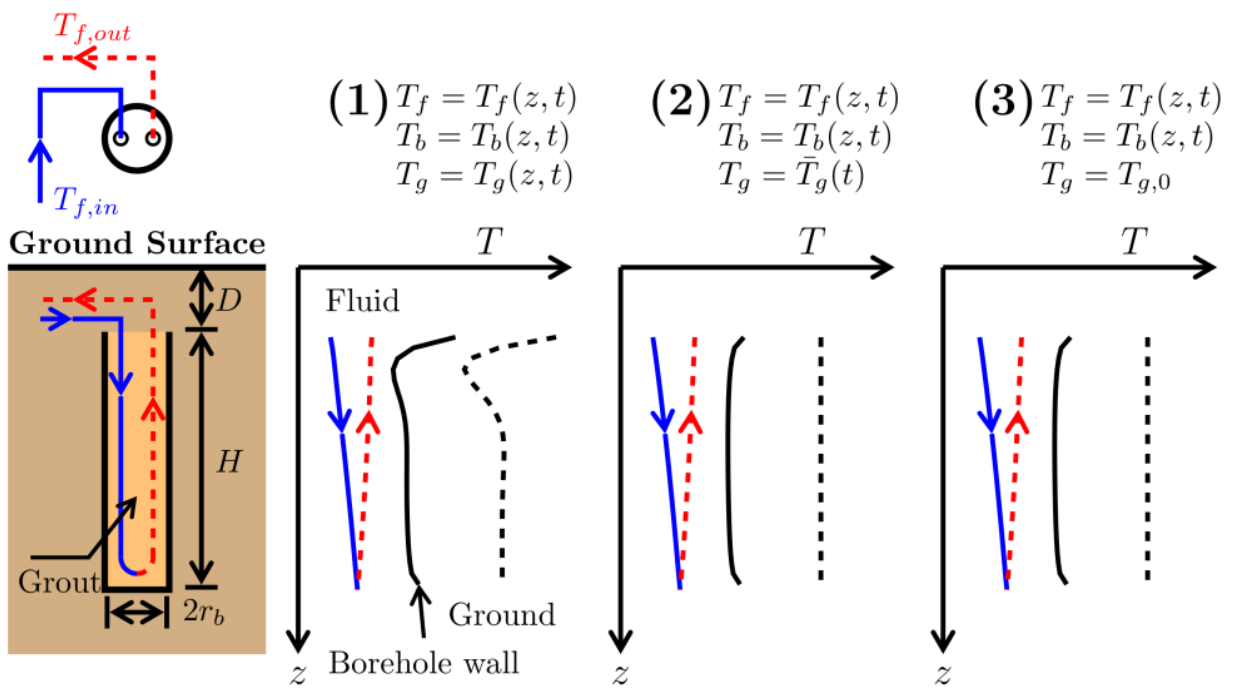

Figure 1 Assumptions used in the calculation of ground temperatures $T_{g}$, borehole wall temperatures $T_{b}$ and fluid temperatures $T_{f}$

While it is recognized that ambient air temperature variations influence ground temperature conditions in geothermal bore fields, it is not clear how much returning fluid temperatures from the boreholes are affected, especially for short boreholes. This study aims to quantify the impact of ambient air temperature variations on 
predicted fluid temperature and its relation with the borehole length and buried depth. Different assumptions for the time- and depth-variation of ground temperatures along the boreholes due to ambient temperature variations are considered, as shown on fig. 1: (1) time-varying non-uniform ground temperature, (2) time-varying uniform ground temperature and (3) constant uniform ground temperature. The relative difference between each assumption on the predicted fluid temperatures are assessed from a simulation case study of a residential geothermal heat pump system. Predicted fluid temperatures are compared for different values of borehole buried depth and borehole length. The validity of each assumption is reported.

\section{MATHEMATICAL MODEL}

The analytical model of Cimmino (2016) is adapted to simulate single U-tube vertical geothermal boreholes in series and is coupled to an analytical solution of the ground temperature variation due to varying ambient air temperatures.

\section{Ground Model}

Each borehole is divided into $n_{q}$ segments of equal lengths. Each of the borehole segments are modeled using the finite line source solution, using one line source per borehole segment. The borehole wall temperature of each segment is obtained by the temporal and spatial superpositions of the finite line source solution. The borehole wall temperature along each of the segments of a borehole $i$ are given by:

$$
\mathcal{L}\left(\boldsymbol{T}_{\boldsymbol{b}, \boldsymbol{i}}(t)\right)=\mathcal{L}\left(\boldsymbol{T}_{\boldsymbol{g}}(t)\right)-\sum_{j=1}^{n_{b}} \mathcal{L}\left(\boldsymbol{\Delta h}_{\boldsymbol{i j}}(t)\right) \cdot \mathcal{L}\left(\boldsymbol{Q}_{\boldsymbol{b}, \boldsymbol{j}}(t)\right) /\left(2 \pi k_{s} H / n_{q}\right)
$$

where $\boldsymbol{T}_{\boldsymbol{b}, \boldsymbol{i}}(t)=\left[T_{b, i, u}(t)\right]$ is a column vector of the borehole wall temperature of each borehole segment $u$ of borehole $i, \boldsymbol{T}_{\boldsymbol{g}}(t)=\left[T_{g, u}(t)\right]$ is a column vector of the average ground temperature along the length of each borehole segment $u, \boldsymbol{Q}_{\boldsymbol{b}, j}(t)=\left[Q_{b, j, v}(t)\right]$ is a column vector of the heat extraction rates of each segment $v$ of borehole $j, \boldsymbol{\Delta} \boldsymbol{h}_{i j}(t)=\left[\Delta h_{i j, u v}(t)\right]$ is a square matrix of the segment-to-segment response factor increments between segments of borehole $j$ and borehole $i . \mathcal{L}(f(t))$ represents the direct Laplace transform of a function $f(t)$. Information on the use of numerical Laplace transforms for the calculation of borehole wall temperatures is given in (Cimmino, et al. 2013; Cimmino and Bernier 2014; Cimmino 2015; Cimmino and Bernier 2015). Segment-to-segment response factor increments are given by the finite line source solution (Claesson and Javed 2011; Cimmino and Bernier 2014).

\section{Surface Effects}

The ground temperature is calculated from the analytical solution to transient heat conduction in semi-infinite media with varying surface temperature, provided by Carslaw and Jaeger (1959). The analytical solution is given by:

$$
\begin{gathered}
\mathcal{L}\left(T_{g}(z, t)-T_{g, 0}\right)=\mathcal{L}\left(T_{\text {air }}(t)-T_{g, 0}\right) \cdot \mathcal{L}\left(f_{g}(z, t)\right) \\
f_{g}(z, t)=\frac{z}{2 \sqrt{\pi \alpha_{s} t^{3}}} \exp \left(-z^{2} / 4 \alpha_{s} t\right)
\end{gathered}
$$

where $T_{g, 0}$ is the initial uniform ground temperature and $T_{\text {air }}(t)$ is the varying ambient air temperature, assumed equal to the ground surface temperature. The ground temperature is averaged over each segment:

$$
\mathcal{L}\left(\boldsymbol{T}_{\boldsymbol{g}}(t)-\mathbf{1}_{n_{q}} T_{g, 0}\right)=\mathcal{L}\left(T_{\text {air }}(t)-T_{g, 0}\right) \cdot \mathcal{L}\left(\boldsymbol{F}_{\boldsymbol{g}}(t)\right)
$$




$$
F_{g, u}(t)=\sqrt{\frac{\alpha_{s}}{\pi t}}\left[\exp \left(\frac{D_{u}^{2}}{4 \alpha_{s} t}\right)-\exp \left(\frac{\left(D_{u}+H / n_{q}\right)^{2}}{4 \alpha_{s} t}\right)\right] / \frac{H}{n_{q}}
$$

where $\boldsymbol{F}_{\boldsymbol{g}}(t)=\left[F_{g, u}(t)\right]$ is a column vector of the functions $F_{g, u}(t)$ and $\mathbf{1}_{n_{q}}$ is a $n_{q} \times 1$ all-ones column vector. The average ground temperature over the borehole lengths is calculated in the same manner:

$$
\begin{gathered}
\mathcal{L}\left(\bar{T}_{g}(t)-T_{g, 0}\right)=\mathcal{L}\left(T_{\text {air }}(t)-T_{g, 0}\right) \cdot \mathcal{L}\left(\bar{F}_{g}(t)\right) \\
\bar{F}_{g}(t)=\sqrt{\frac{\alpha_{s}}{\pi t}}\left[\exp \left(\frac{D^{2}}{4 \alpha_{s} t}\right)-\exp \left(\frac{(D+H)^{2}}{4 \alpha_{s} t}\right)\right] / H
\end{gathered}
$$

where $\bar{T}_{g}(t)$ is the average temperature over the length of the boreholes.

\section{Borehole Model}

Fluid temperatures in the boreholes are calculated from the steady-state line source approximation (Hellstrom 1991). An analytical method was recently proposed by Cimmino (2016) for boreholes with any number of U-tubes and varying borehole wall temperatures. The solution is adapted here for single U-tube boreholes. Borehole thermal resistances give the relation between the fluid and borehole wall temperatures and the pipe heat transfer rates:

$$
\boldsymbol{T}_{\boldsymbol{f}, i}(z, t)-\mathbf{1}_{2} T_{b, i}(z, t)=\boldsymbol{R} \boldsymbol{q}_{i}(z, t)
$$

where $\boldsymbol{T}_{f, i}(z)=\left[\begin{array}{l}T_{f, i, 1}(z) \\ T_{f, i, 2}(z)\end{array}\right]$ is column vector of the fluid temperature in each pipe of borehole $i$, with $T_{f, i, 1}(z)$ the temperature in the downward flowing pipe and $T_{f, i, 2}(z)$ the temperature in the upward flowing pipe, $\boldsymbol{q}_{\boldsymbol{i}}(z, t)=$ $\left[\begin{array}{l}q_{i, 1}(z, t) \\ q_{i, 2}(z, t)\end{array}\right]$ is a column vector of the heat transfer rates of each of the pipes in borehole $i$, and $\boldsymbol{R}=\left[\begin{array}{ll}R_{11} & R_{12} \\ R_{21} & R_{22}\end{array}\right]$ is the matrix of borehole thermal resistances, with coefficients calculated from the line source approximation (Hellstrom 1991).

The inverse of eq. (8) and the thermal energy balance of the fluid along the pipe length yields a system of differential equations:

$$
\frac{\partial \boldsymbol{T}_{f, i}}{\partial z}(z, t)=\boldsymbol{A} \boldsymbol{T}_{f, i}(z, t)-\boldsymbol{A} \mathbf{1}_{2} T_{b, i}(z, t)
$$

where $\boldsymbol{A}=\left[\begin{array}{ll}A_{11} & A_{12} \\ A_{21} & A_{22}\end{array}\right]=\left[\begin{array}{cc}-S_{11} / \dot{m} c_{f} & -S_{12} / \dot{m} c_{f} \\ S_{21} / \dot{m} c_{f} & S_{22} / \dot{m} c_{f}\end{array}\right]$ is the coefficient matrix of the system of differential equations, with $\boldsymbol{R}^{-1}=\left[\begin{array}{ll}S_{11} & S_{12} \\ S_{21} & S_{22}\end{array}\right]$ the inverse of the borehole resistance matrix.

The fluid temperature profiles are given by the matrix exponential of $\boldsymbol{A} z$. The fluid temperature profiles in borehole $i$ with uniform borehole wall temperature along each of the borehole segments is given by (Cimmino 2016):

$$
\boldsymbol{T}_{f, i}(z, t)=\boldsymbol{E}(z) \boldsymbol{T}_{f, i}(0, t)-\sum_{v=1}^{\left\lceil\frac{z}{H} \cdot n_{q}\right\rceil} \int_{\frac{(v-1) \cdot H}{n_{q}}}^{\min \left(z \frac{v \cdot H}{n_{q}}\right)} \boldsymbol{E}\left(z-z^{\prime}\right) \boldsymbol{A} \mathbf{1}_{2} T_{b, i, v}(t) d z^{\prime}
$$

where $\boldsymbol{E}(z)=\left[\begin{array}{ll}E_{11}(z) & E_{12}(z) \\ E_{21}(z) & E_{22}(z)\end{array}\right]=\exp (\boldsymbol{A} z)=\boldsymbol{V} \exp (\boldsymbol{D} z) \boldsymbol{V}^{-1}$ is the matrix exponential of $\boldsymbol{A} z, \boldsymbol{D}$ is a diagonal matrix of the eigenvalues of $\boldsymbol{A}$ and $\boldsymbol{V}$ is the matrix of the column eigenvectors of $\boldsymbol{A}$.

The relation between inlet and outlet temperatures is obtained by imposing equal fluid temperatures $T_{f, i, 1}=$ 
$T_{f, i, 2}$ at the bottom end of the borehole $(z=H)$ :

$$
E_{\text {out }}(H) T_{f, \text { out }, i}(t)=E_{\text {in }}(H) T_{f, \text { in }, i}(t)+\boldsymbol{E}_{\boldsymbol{b}}(H) \boldsymbol{T}_{\boldsymbol{b}, \boldsymbol{i}}(t)
$$

where $E_{\text {out }}(z)=E_{12}(z)-E_{22}(z)$ and $E_{\text {in }}(z)=E_{21}(z)-E_{11}(z)$ are coefficients obtained from the matrix exponential. $\boldsymbol{E}_{\boldsymbol{b}}=\left[E_{b, v}\right]$ is a line vector of coefficients for each of the borehole segments, given by:

$$
E_{b, v}(\mathrm{z})=\left[\begin{array}{ll}
1 & -1
\end{array}\right] \boldsymbol{V} \boldsymbol{D}^{-1}\left(\exp \left(\boldsymbol{D}\left(H-(v-1) \cdot H / n_{q}\right)\right)-\exp \left(\boldsymbol{D}\left(H-v \cdot H / n_{q}\right)\right)\right) \boldsymbol{V}^{-1} \boldsymbol{A} \mathbf{1}_{2}
$$

\section{Full Model}

The borehole model is coupled to the ground model through energy balances along each segment of each borehole. Fluid temperature variations along a borehole segment may be calculated from eq. (10). The heat extraction rate of the borehole segment is then equal to the net heat gain along all pipes:

$$
\boldsymbol{Q}_{\boldsymbol{b}, \boldsymbol{i}}(t)=-\boldsymbol{\Delta} \boldsymbol{E}_{\text {in }} T_{f, \text { in }, i}(t)+\boldsymbol{\Delta} \boldsymbol{E}_{\text {out }} T_{f, \text { out }, i}(t)-\boldsymbol{\Delta} \boldsymbol{E}_{\boldsymbol{b}} \boldsymbol{T}_{\boldsymbol{b}, \boldsymbol{i}}(t)
$$

where $\boldsymbol{\Delta} \boldsymbol{E}_{\text {in }}=\left[\Delta E_{\text {in,u }}\right]$ and $\boldsymbol{\Delta} \boldsymbol{E}_{\text {out }}=\left[\Delta E_{\text {out }, u}\right]$ are column vectors of coefficients, with $\Delta E_{\text {in }, u}=$ $\dot{m} c_{f}\left(E_{\text {in }}\left(\frac{u}{n_{q}} \cdot H\right)-E_{\text {in }}\left(\frac{(u-1)}{n_{q}} \cdot H\right)\right) \quad$ and $\quad \Delta E_{\text {out }, u}=\dot{m} c_{f}\left(E_{\text {out }}\left(\frac{u}{n_{q}} \cdot H\right)-E_{\text {out }}\left(\frac{(u-1)}{n_{q}} \cdot H\right)\right), \quad$ and $\quad \boldsymbol{\Delta} E_{\boldsymbol{b}}=$ $\left[\Delta E_{b, u v}\right]$ is a matrix of coefficients, with:

$$
\Delta E_{b, u v}=\left\{\begin{array}{cc}
0 & \text { for } u<v \\
\dot{m} c_{f} E_{b, v}\left(u H / n_{q}\right) & \text { for } u=v \\
\dot{m} c_{f}\left(E_{b, v}\left(u H / n_{q}\right)-E_{b, v}\left((u-1) H / n_{q}\right)\right) & \text { for } u>v
\end{array}\right.
$$

As the boreholes are connected in series, the outlet fluid temperature from borehole $(i)$ is equal to the inlet temperature into the next borehole $(i+1)$. Finally, the total heat extracted from the bore field is equal to the sum of the heat extracted from all boreholes:

$$
\boldsymbol{Q}(t)=\boldsymbol{B}_{\text {in }} \boldsymbol{T}_{\boldsymbol{f}, \text { in }}(t)+\boldsymbol{B}_{\text {out }} \boldsymbol{T}_{\boldsymbol{f}, \text { out }}(t)
$$

where $\boldsymbol{Q}(t)=\left[\begin{array}{c}\mathbf{0}_{n_{b}-1 \times 1} \\ Q_{\text {tot }}(t)\end{array}\right]$ is a column vector, with $\mathbf{0}_{n_{b}-1 \times 1}$ a $n_{b}-1 \times 1$ all-zeros column vector and $Q_{t o t}$ is the total heat extraction rate from the bore field, $\boldsymbol{B}_{\boldsymbol{i n}}=\left[\begin{array}{cc}\mathbf{0}_{n_{b}-1 \times 1} & \boldsymbol{I}_{n_{b}-1} \\ -\dot{m} c_{f} & \mathbf{0}_{1 \times n_{b}-1}\end{array}\right]$ and $\boldsymbol{B}_{\boldsymbol{o u t}}=\left[\begin{array}{cc}-\boldsymbol{I}_{n_{b}-1} & \mathbf{0}_{n_{b}-1 \times 1} \\ \mathbf{0}_{1 \times n_{b}-1} & \dot{m} c_{f}\end{array}\right]$ are coefficient matrices, with $\boldsymbol{I}_{n_{b}-1}$ the $n_{b}-1 \times n_{b}-1$ identity matrix, and $\boldsymbol{T}_{\boldsymbol{f}, \boldsymbol{i n}}=\left[T_{f, \text { in }, i}\right]$ and $\boldsymbol{T}_{\boldsymbol{f}, \boldsymbol{o u t}}=\left[T_{f, \text { out }, i}\right]$ are column vectors of the inlet and outlet fluid temperatures into each borehole in the bore field.

Eqs. $(1,4,11,13,15)$ can be assembled to obtain a system of linear equations in the Laplace domain, which gives the relation between the heat extraction rates and borehole wall temperatures of all borehole segments, and the inlet and outlet fluid temperatures of all boreholes.

\section{RESULTS}

The proposed model is used to study the effects of ambient air temperature variations on the predicted fluid temperatures. Three assumptions of decreasing complexity for the calculation of ground temperatures are compared: (1) time- and depth-varying ground temperature, as obtained from eq. (4), (2) time-varying uniform ground temperature $\boldsymbol{T}_{\boldsymbol{g}}(t)=\bar{T}_{g}(t)$, as obtained from eq. (6), and (3) constant uniform temperature $\boldsymbol{T}_{\boldsymbol{g}}(t)=T_{g, 0}$. 
A geothermal system was simulated using the three previously defined assumptions for ground temperature variations with different number of equidistant boreholes on a straight line ranging from $n_{b}=1$ to 50 , using the same total heat extraction rate and total borehole length in the bore field. All boreholes are positioned on a single line and connected in series. The total heat extraction rate, shown on fig. 2, is obtained from the simulation of a single family home (Kegel, et al. 2012). A constant heat pump coefficient of performance (COP) of 3 in both heating and cooling modes and a heat pump capacity of $10 \mathrm{~kW}$ were assumed to obtain the heat extraction rates from the building loads. The peak heat extraction and heat injection rates are $6.67 \mathrm{~kW}$ and $5.61 \mathrm{~kW}$ respectively. The total yearly thermal energy extracted from and injected into the ground are $19190 \mathrm{kWh}$ and $2243 \mathrm{kWh}$, respectively. The ambient air temperatures are obtained from TMY2 weather data for Montreal, Canada. The calculated ground temperature profiles from eq. (4) are shown on fig. 2 for different times of the year. The simulation parameters are presented in Table 1.
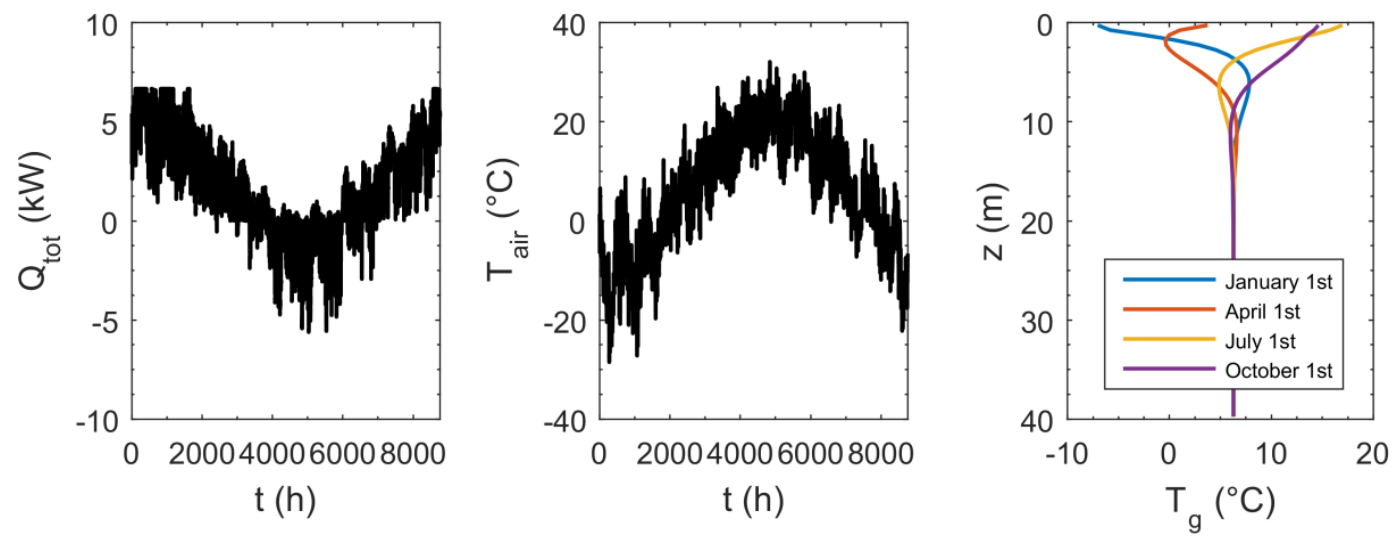

Figure 2 Total heat extraction rates in the bore field (left), ambient air temperatures (center), and ground temperature profiles (right)

The maximum absolute predicted dimensionless outlet fluid temperature difference between each of assumptions (2) and (3) and assumption (1) are obtained for fields of $n_{b}=1,2,3,4,5,6,7,10,15,20,25,30,35,40$ and 50 boreholes and for buried depths $D=2,3$ and $4 \mathrm{~m}$. The dimensionless outlet fluid temperature difference is defined as:

$$
\Delta \Theta(t)=\frac{T_{f, \text { out }}^{(i)}(t)-T_{f, \text { out }}^{(1)}(t)}{T_{g, 0}-T_{f, \text { out }}^{(1)}(t)}
$$

where $T_{f, \text { out }}^{(i)}(t)$ is the outlet fluid temperature of the $n_{b}$-th borehole calculated using assumption $(i)$ defined above. The maximum predicted dimensionless outlet fluid temperature differences are shown on fig. 3 as a function of the portion of the borehole located above the thermal penetration depth $D_{T}=\sqrt{\alpha_{S} t_{T}}$, where $t_{T}=\frac{\pi}{2}$ years is the characteristic thermal penetration time. It is shown that the maximum absolute difference in predicted outlet fluid temperatures calculated using assumptions (1) and (3) increase linearly with increasing portion of the borehole above the penetration depth. A $2 \%$ difference is obtained when approximately $8 \%$ of the borehole is above the penetration depth. The maximum absolute difference in predicted outlet fluid temperatures calculated using assumptions (1) and (2) are much lower: the maximum absolute difference is less than $1.5 \%$ for all studied cases. The maximum absolute 
difference also decreases after reaching a maximum value between $35 \%$ and $50 \%$ of the borehole above the thermal penetration depth.

Table 1. Simulation Parameters

\begin{tabular}{ccccc}
\hline Parameter & Value & Units & Value & Units \\
\hline \hline Simulation time step & 1 & $\mathrm{~h}$ & & \\
Maximum time & 10 & years & & \\
Total borehole length & 350 & $\mathrm{~m}$ & 1150 & $\mathrm{ft}$ \\
Buried depth & 2 to 4 & $\mathrm{~m}$ & 6.5 to 13.1 & $\mathrm{ft}$ \\
Borehole spacing & 5 & $\mathrm{~m}$ & 16.4 & $\mathrm{ft}$ \\
Borehole radius & 0.075 & $\mathrm{~m}$ & 3 & $\mathrm{in}$. \\
Pipe outer radius & 0.021 & $\mathrm{~m}$ & 0.83 & in. \\
Pipe inner radius & 0.017 & $\mathrm{~m}$ & 0.67 & $\mathrm{in}$. \\
Shank spacing & 0.053 & $\mathrm{~m}$ & 2.07 & $\mathrm{in}$. \\
Undisturbed ground temperature & 6.3 & ${ }^{\circ} \mathrm{C}$ & 43.34 & ${ }^{\circ} \mathrm{F}$ \\
Ground thermal conductivity & 2.5 & $\mathrm{~W} / \mathrm{m}-\mathrm{K}$ & 17.33 & $\mathrm{BTU}-\mathrm{in} . / \mathrm{h}-\mathrm{ft}-{ }^{\circ} \mathrm{F}$ \\
Ground thermal diffusivity & $1 \times 10^{-6}$ & $\mathrm{~m}{ }^{2} / \mathrm{s}$ & $1.08 \times 10^{-5}$ & $\mathrm{ft} / \mathrm{s}$ \\
Grout thermal conductivity & 1.5 & $\mathrm{~W} / \mathrm{m}-\mathrm{K}$ & 10.40 & $\mathrm{BTU}-\mathrm{in} . / \mathrm{h}-\mathrm{ft}^{\circ}{ }^{\circ} \mathrm{F}$ \\
Pipe thermal conductivity & 0.4 & $\mathrm{~W} / \mathrm{m}-\mathrm{K}$ & 2.77 & $\mathrm{BTU}-\mathrm{in} . / \mathrm{h}-\mathrm{ft}^{\circ}{ }^{\circ} \mathrm{F}$ \\
Fluid thermal conductivity & 0.45 & $\mathrm{~W} / \mathrm{m}-\mathrm{K}$ & 3.12 & $\mathrm{BTU}-\mathrm{in} . / \mathrm{h}-\mathrm{ft}^{\circ} \mathrm{F}$ \\
Fluid dynamic viscosity & $4 \times 10^{-3}$ & $\mathrm{~Pa}-\mathrm{s}$ & $8.35 \times 10^{-5}$ & $1 \mathrm{bf}-\mathrm{s} / \mathrm{ft}^{2}$ \\
Fluid density & 1030 & $\mathrm{~kg} / \mathrm{m}{ }^{3}$ & 64.3 & $\mathrm{lbm} / \mathrm{ft}^{3}$ \\
Fluid specific heat & 4000 & $\mathrm{~J} / \mathrm{kg}-\mathrm{K}$ & 0.956 & $\mathrm{BTU} / \mathrm{lbm}-{ }^{\circ} \mathrm{F}$ \\
Fluid flow rate & 0.75 & $\mathrm{~kg} / \mathrm{s}$ & 1.65 & $\mathrm{lbm} / \mathrm{s}$ \\
\hline
\end{tabular}
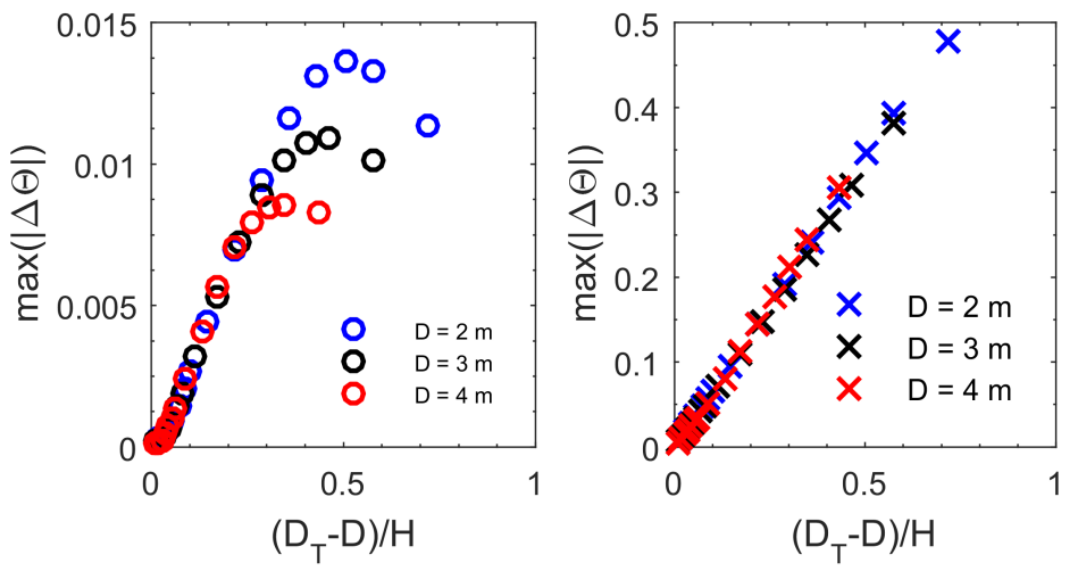

Figure 3 Maximum absolute dimensionless outlet fluid temperature difference relative to assumption (1) for each of assumption (2) (left) and assumption (3) (right)

\section{CONCLUSION}

A simulation model for geothermal bore fields was presented. The finite line source solution was used to calculate borehole wall temperatures, while a steady-state analytical solution of the interaction between the fluid in the U-tube pipes and the borehole wall was used to calculate the outlet fluid temperature. Different assumptions were considered for the calculation of ground temperature profiles to account for ambient air temperature variations: (1) 
time-varying non-uniform ground temperature, (2) time-varying uniform ground temperature and (3) constant uniform ground temperature. The model was adapted to simulate fields of geothermal boreholes connected in series.

The model was used to simulate a residential geothermal heat pump system with boreholes connected in series. Predicted fluid temperatures were obtained for bore fields with numbers of boreholes ranging from 1 to 50 boreholes and corresponding borehole lengths from $350 \mathrm{~m}$ down to $7 \mathrm{~m}$. The borehole buried depth also varied from $2 \mathrm{~m}$ to $4 \mathrm{~m}$. It is shown that detailed time- and depth-variation modeling of ground variations is not needed to accurately predict fluid temperatures. A time-varying uniform ground temperature profiles results in predicted fluid temperatures within $1.5 \%$ of those obtained with time-varying non-uniform ground temperatures.

While it was shown that ambient temperature variations may significantly affect fluid temperatures in short boreholes, some limitations of the present model need to be addressed to correctly assess the efficiency of systems using short boreholes. For instance, for short boreholes, ground thermal properties variations along the depth of the boreholes might also have an important impact on fluid, borehole and near-surface ground temperatures.

\section{NOMENCLATURE}

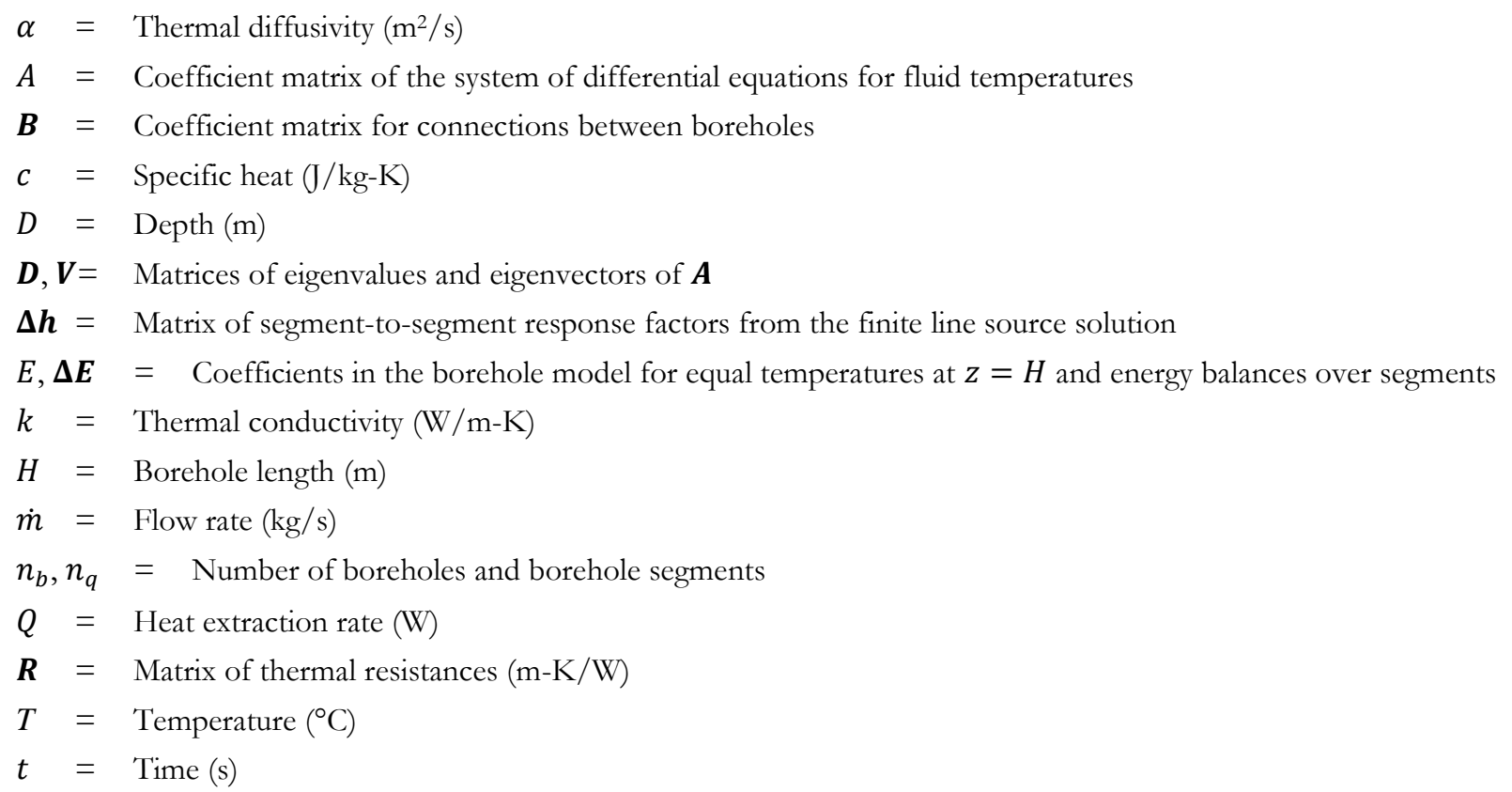

\section{Subscripts}

$$
\begin{aligned}
& \text { air }=\text { air } \\
& b=\text { borehole } \\
& f=\text { fluid } \\
& g, s=\text { ground } \\
& i, j=\text { borehole indexes } \\
& \text { in }=\text { inlet } \\
& \text { out }=\text { outlet } \\
& T=\text { thermal penetration } \\
& u, v=\text { borehole segment indexes } \\
& 0=\text { initial }
\end{aligned}
$$




\section{REFERENCES}

Bandos, T. V., Á. Montero, P. J. Fernández de Córdoba and J. F. Urchueguía. 2011. Improving parameter estimates obtained from thermal response tests: Effect of ambient air temperature variations. Geothermics 40(2): 136-143.

Bandos, T. V., Á. Montero, E. Fernández, J. L. G. Santander, J. M. Isidro, J. Pérez, P. J. Fernández de Córdoba and J. F. Urchueguía. 2009. Finite line-source model for borehole heat exchangers: effect of vertical temperature variations. Geothermics 38(2): 263-270.

Carslaw, H. S. and J. C. Jaeger. 1959. Conduction of heat in solids. 2nd ed, Oxford: Clarendon Press.

Cimmino, M. 2015. The effects of borehole thermal resistances and fluid flow rate on the g-functions of geothermal bore fields. International Journal of Heat and Mass Transfer 91: 1119-1127.

Cimmino, M. 2016. Fluid and borehole wall temperature profiles in vertical geothermal boreholes with multiple U-tubes. Renewable Energy 96, Part A: 137-147.

Cimmino, M. and M. Bernier. 2014. A semi-analytical method to generate g-functions for geothermal bore fields. International Journal of Heat and Mass Transfer 70(c): 641-650.

Cimmino, M. and M. Bernier. 2015. Experimental determination of the g-functions of a small-scale geothermal borehole. Geothermics 56: 60-71.

Cimmino, M., M. Bernier and F. Adams. 2013. A contribution towards the determination of g-functions using the finite line source. Applied Thermal Engineering 51(1-2): 401-412.

Claesson, J. and S. Javed. 2011. An analytical method to calculate borehole fluid temperatures for time-scales from minutes to decades. ASHRAE Transactions 117(2): 279-288.

Eskilson, P. 1987. Thermal Analysis of Heat Extraction Boreboles. Ph.D. Thesis, University of Lund.

Fisher, D. E., S. J. Rees, S. K. Padhmanabhan and A. Murugappan. 2006. Implementation and validation of ground-source heat pump system models in an integrated building and system simulation environment. HVAC\&R Research 12(3A): 693-710.

Hellstrom, G. 1991. Ground heat storage: Thermal analysis of duct storage systems. Ph.D. Thesis, University of Lund.

Hellström, G. and B. Sanner. 1994. Software for dimensioning of deep boreholes for beat extraction. Proceedings of Calorstock 1994, Espoo/Helsinki, Finland.

Kegel, M., J. Tamasauskas, R. Sunye and A. Langlois. 2012. Assessment of a Solar Assisted Air Source and a Solar Assisted Water Source Heat Pump System in a Canadian Household. Energy Procedia 30: 654-663.

Lamarche, L. and B. Beauchamp. 2007. A new contribution to the finite line-source model for geothermal boreholes. Energy and Buildings 39(2): 188-198.

Lazzarotto, A. 2016. A methodology for the calculation of response functions for geothermal fields with arbitrarily oriented boreboles - Part 1. Renewable Energy 86: 1380-1393.

Lazzarotto, A. and F. Björk. 2016. A methodology for the calculation of response functions for geothermal fields with arbitrarily oriented boreboles - Part 2. Renewable Energy 86: 1353-1361.

Liu, X. and G. Hellstrom. 2006. Enhancements of an integrated simulation tool for ground-source heat pump system design and energy analysis. Proc. 10th International Conference on Thermal Energy Storage, Richard Stockton College of New Jersey.

Marcotte, D. and P. Pasquier. 2014. Unit-response function for ground heat exchanger with parallel, series or mixed borehole arrangement. Renewable Energy 68: 14-24.

Molina-Giraldo, N., P. Blum, K. Zhu, P. Bayer and Z. Fang. 2011. A moving finite line source model to simulate borehole beat exchangers with groundwater advection. International Journal of Thermal Sciences 50(12): 2506-2513.

Rivera, J. A., P. Blum and P. Bayer. 2015. Analytical simulation of groundwater flow and land surface effects on thermal plumes of borehole heat exchangers. Applied Energy 146: 421-433.

Rivera, J. A., P. Blum and P. Bayer. 2016. A finite line source model with Cauchy-type top boundary conditions for simulating near surface effects on borehole beat exchangers. Energy 98: 50-63.

Spitler, J. D. 2000. A design tool for commercial building loop heat exchangers. Fourth International Heat Pumps in Cold Climates Conference, Aylmer, Québec.

Zarrella, A. and P. Pasquier. 2015. Effect of axial heat transfer and atmospheric conditions on the energy performance of GSHP systems: A simulation-based analysis. Applied Thermal Engineering 78: 591-604.

Zeng, H. Y., N. R. Diao and Z. H. Fang. 2002. A finite line-source model for boreholes in geothermal heat exchangers. Heat Transfer Asian Research 31(7): 558-567. 